\title{
Molecular Dynamic Studies of the Vacancies Interaction with the Grain Boundaries
}

\author{
A. S. Dragunov \\ American University of Nigeria \\ Nigeria \\ Adamawa State \\ Yola By-Pass 98 LamidoZubairu Way
}

\author{
A.V. Weckman, B.F. Demyanov \\ Altai State Technical University \\ Russia \\ Altai Region \\ Barnaul
}

\begin{abstract}
In this paper the method of molecular dynamics used to study the interaction of lattice vacancies with symmetric tilt grain boundaries (GBs) in aluminum. A linear dependence between the number of captured vacancies and the distance to the GB's plane was found. The average rate of vacancy migration to the border decreases exponentially with increasing distance between the plane of the GB and the vacancy. Capture's radius is limited to 2-3 lattice parameters and increases with increasing temperature. Defined four types of boundaries in different ways of interacting with lattice vacancies.
\end{abstract}

Keywords-grain boundary; self-diffusion; computer simulations; aluminum

\section{INTRODUCTION}

For quite a long time by various experimental techniques, such as [1-3] have shown that grain boundaries (GB) acting as sources and sinks of vacancies. By now also experimentally found that the effectiveness of the boundaries as sources (sinks) of vacancies depends on the type boundaries: the boundary are highly arbitrary sources (sinks) even with vacancy's low chemical potential and special GB which do not act as potential sinks [4]. However, at very high chemical potential even coherent twin boundaries are sources (sinks) vacancies, although their effectiveness is less than the arbitrary boundaries [2].

Modern researches have also shown that GB actively interacts with point defects in poly crystals. For example in [5] by computer simulation discussed interaction of vacancies with special grain boundaries. It is shown that the interaction of vacancies with GB essentially depends on the atomic structure of GB. Found on GB regions of alternating tension and compression leads to an oscillatory dependence of the interaction energy of vacancies from the distance from the border. The interaction energy of vacancy with GB is negative, i.e., border is a sink of vacancies. A similar result was obtained in [6] who studied the energy of formation and migration mechanisms of vacancies near the plane of the special GBs. Computer modeling was carried out by using molecular static, molecular dynamic and Monte Carlo method. The authors note that the vacancies can be moved by simple jumps and through collective atomic displacements. In [7-8] studied energy of formation and the activation energy for vacancy migration. Calculations showed that the vacancy formation energy in all investigated borders does not depend on the applied external tensile, but the volu me and enthalpy of formation can vary considerably.
In all shown examples, it is a vacancy which is close to the plane of GB, i.e. actually are elements of the structure of the border. In our paper we present the results of computer simulation of the interaction tilt boundaries with lattice vacancies placed in the bulk grain.

\section{MODEL}

The study was carried out by the method of molecular dynamics. As the initial structure of GB was used atomic structure obtained in the computer experiment are described in detail in [9].Interatomic interaction potential parameters correspond to aluminum. In this model studied the interaction of grain's vacancies with symmetrical GB general and special type with axes misorientation [100], [110] and [111].As shown in [9] energy GB of general type is weakly dependent on the angle of misorientation, so from the entire spectrum of misorientation boundaries of general type with misorientation angles $10^{\circ}, 30^{\circ}$ and $50^{\circ}$ we re chosen. The sample for the study of special boundaries was determined by the following considerations: the misorientation angles capture the entire area of special misorientation boundaries; $\Sigma$ parameter has both large and small values; identity period does not exceed twenty lattice parameters. The main crystallographic parameters (angle of misorientation $(\Theta)$, the inverse density of coincident nodes $(\Sigma)$ and the Millerindices of the plane GB (hkl)) for special boundaries are shown in Table. 1.

TABLE I. CRYSTALLOGRAPHIC CHARACTERISTICS OF SPECIAL GBS.

\begin{tabular}{|l|l|l|}
\hline \multicolumn{2}{|l|}{,} & Hkl \\
\hline$[100]$ & 13 & 015 \\
\hline 22.62 & 5 & 013 \\
\hline 36.87 & 5 & 012 \\
\hline 53.13 & 33 & 118 \\
\hline$[110]$ & 27 & 115 \\
\hline 20.05 & 11 & 113 \\
\hline 31.59 & 21 & 145 \\
\hline 50.48 & 39 & 257 \\
\hline$[111]$ & 3 & 112 \\
\hline 21.79 & & \\
\hline 32.20 & & \\
\hline 60 &
\end{tabular}

After constructing the GB, near the border's plane eight vacancies were placed at different distances from the plane of GB (Fig. 1), where 'a' - lattice parameter. Strictly speaking, the vacancy can't be placed accurately on these positions in connection with the distance that the bicrystal has a discrete 
atomic structure. The program found the nearest to the "reference point" atom and removes it.

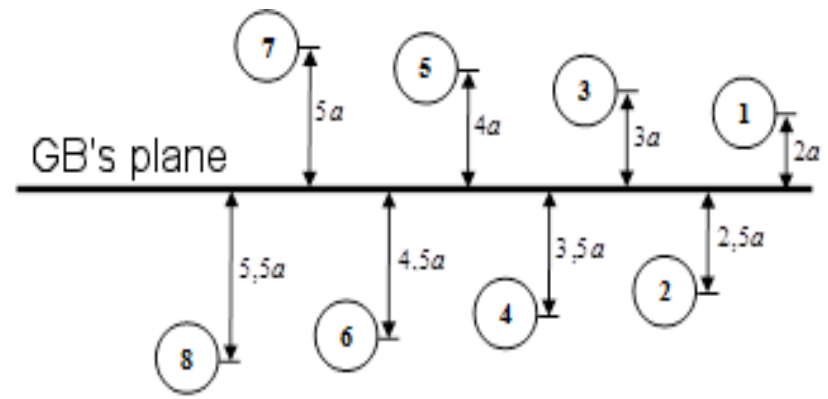

FIGURE I. LOCATION VACANCIES NEAR THE GRAIN BOUNDARY PLANE.

For convenience of presentation vacancies were numbered as the distance from the GB.Later in the dynamic relaxation tracked all jumps of atoms and with using the Visualizer was built three-dimensional picture, on which jumps of atoms represented by the segment.

The boundaries have excess volume, which is associated with the existence of a defect of distributed vacancies [10]. Because of this, most of the jumps occur in the plane the GB and this making it difficult to analyze the movement of vacancies. Therefore, using special software, the jumps of atoms are removed, and the movement of vacancies was built in the chain.

Fig. 2a shows a picture of the small-angle the GB jumps atoms $\Theta=10^{\circ}$ with the axis of misorientation [100] at $\mathrm{T}=600$ $\mathrm{K}$, and Fig. $2 \mathrm{~b}$ is the same after the data processing boundary.

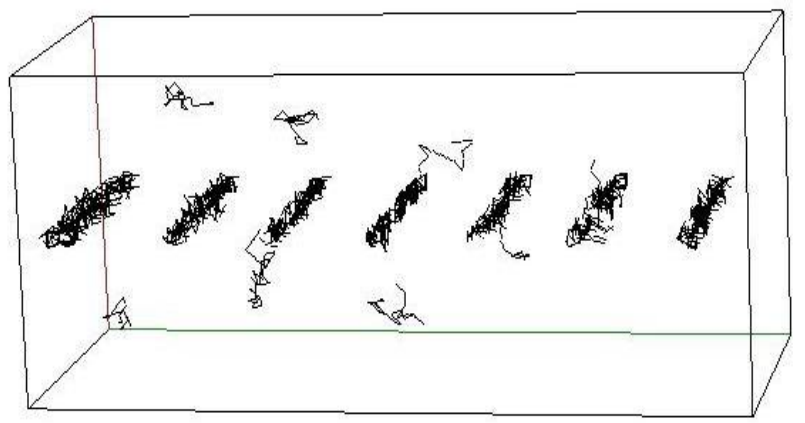

(a)

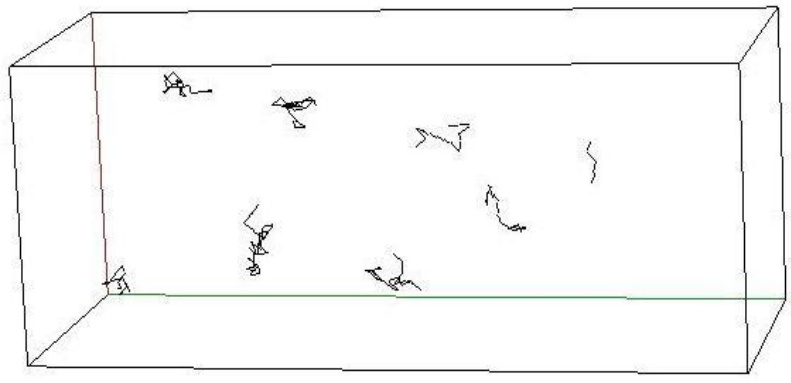

(b)

FIGURE II. THE SPATIAL PATTERN OF JUMPS OF ATOMS FOR GENERAL T YPE GB $=10$ WITH THE AXIS OF DISORIENTATION [100] AT T = $600 \mathrm{~K}$ : A) - BEFORETHE DATA PROCESSING; B) AFTERTHE DAT APROCESSING.

\section{RESULTS AND DISCUSSION}

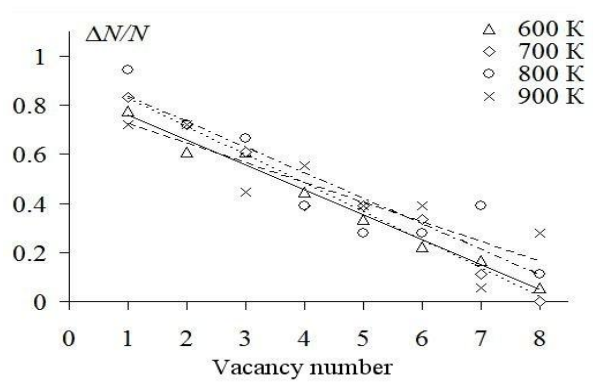

a)

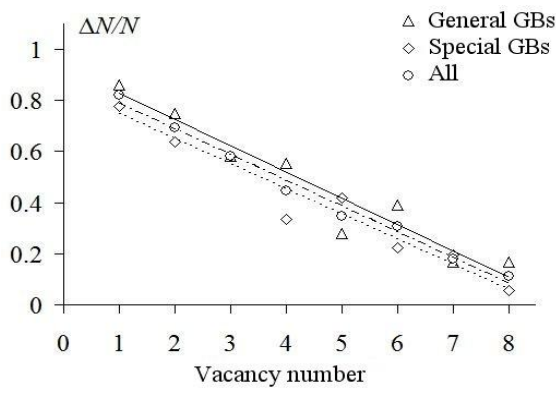

b)

FIGURE III. AMOUNT OF VACANCIES HAVE REACHED GBS AT DIFFERENT TEMPERATURES (A) AND FOR DIFFERENT TYPES OF GBS (B).

The study of borders was carried out at the temperatures of $600 \mathrm{~K}, 700 \mathrm{~K}, 800 \mathrm{~K}$ and $900 \mathrm{~K}$. The calculations showed that the displacement of lattice vacancies is generally random. For instance, as shown in Figure $2 b$ three most closest to the plane of the GB vacancies after a nu mber of are hopping appeared in the border.However, for the same boundary at $800 \mathrm{~K}$ vacancy "1" misses the border, and the vacancy "7" is in it.At a temperature of $900 \mathrm{~K}$ vacancy "3" distant from the plane the GB, whereas vacancies "4", "5" and "6" on the contrary come to the border.In this regard, conclusions on the interaction of the border with the vacancies can be done only on the basis of statistical data. Fig. 3 presents statistics on the number vacancies $\Delta \mathrm{N}$ have reached plane the GB.

The total number $N$ of vacancies was 18 . The horizontal scale deferred nu mbers of vacancies in accordance with Fig. 1. Given that the distance from the GB plane to the vacancy is linearly dependent on its number, it can be concluded that the probability of vacancy capture by GB is inversely proportional to the distance from the GB to the vacancy.Fig. 3a also shows that the relationship is practically independent from temperature. Deviation from linearity, probably due to a small number of examined GBs. As for the statistics of the individual axes of misorientation, their views differ from the graphs shown in Fig. Except that the scatter due to the small number of GB more significant.

In statistical sample participated as special and general GBs. In this regard it is of interest to consider the statistics boundaries separately. Fig. $3 b$ shows statistics vacancies came to the border for the general and special GB individually, as well as the entire spectrum of GB without temperature. Here too there is a linear dependence on the distance between the vacancy and the plane GB. 
The average rate of migration of vacancies can characterize the strength of interaction of vacancies with GB. Fig. 4 shows the average speed of vacancies migration at various temperatures over the entire ensemble of boundaries. There were only those vacancies that in the migration process reach the area GBs.

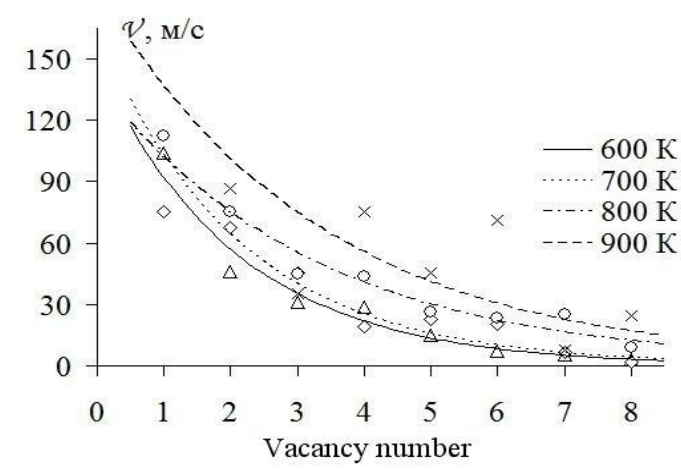

a)

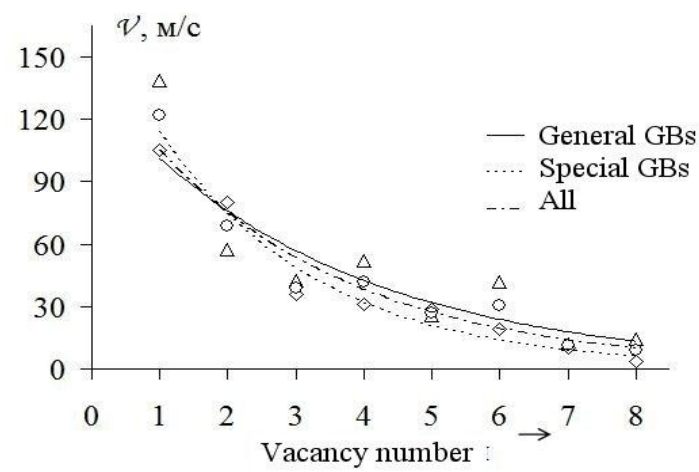

b)

FIGURE IV.

THE AVERAGE MIGRATION RATE OF

VACANCIES AT VARIOUS TEMPERATURES FROM (A) AND FOR DIFFERENT TYPES OF GBS (B).

On all four graphs there is a clear exponential dependence, and the exponent decreases linearly with increasing temperature. The validity of this approximation has high values generated except for a temperature of $900 \mathrm{~K}$, which is probably due to the high mobility of the atoms on the one side and a small number of experiments conducted with the other Fig. $4 b$ shows the dependence of the average rate of vacancy migration to GB without temperature. Depending also has an exponential form for both general and special GB type and for the whole ensemble of boundaries

We can assume that the reduction in the rate of vacancy migration away from the boundary associated with the ability to attract vacancy GB. However, in order to evaluate this not enough to be limited with an average results.

To clarify this is sue has been investigated the tracks of atoms which came to GBs. Fig. 5 shows the typical dependence of the position of vacancies $(\Delta y$ - distance from the vacancy to the plane GB) with respect to the grain boundaries of time. The nu mbers "1", "2" ... marked a vacancy in accordance with Fig. 1 and from the whole ensemble chosen only one characteristic track of vacancies at a temperature of $600 \mathrm{~K}$.
The figure shows that nearest to GB vacancy come to the border almost immediately. Vacancies that are far away from the border come to GB only as a result of random walks will not get into a certain area in the vicinity of the boundary corresponds to two or three lattice parameters. Thus, we can talk about a value which is usually referred to as the capture range. However finding a vacancy at a distance less than the radius of capture does not mean its absolute arrival to GBs. Moreover, as can be seen from Fig. 3a, only about $82 \%$ of vacancies "1" are trapped by GB.

Statistical processing for the capture radius $\Delta y_{к р} G B$ and speed of the captured of vacancies $V_{\text {кр }}$ is shown in Fig. 6. The figure shows (Fig. 6a) that with increasing temperature the capture radius GB increases. Dependence is close to linear, but increasing is not more than $20 \%$. Velocity of the captured vacancies differs significantly from the average migration velocity (Fig. 4), which is obviously related to the impact of the border for the vacancy. Velocity linearly increase with increasing temperature.

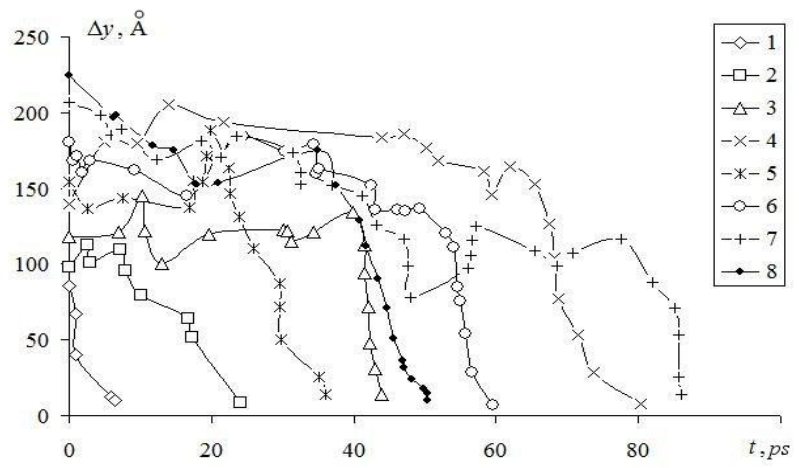

FIGURE V. DEPENDENCE OF THE VACANCIES POSITIONS RELATIVE TO THE PLANE GBS FROM TIME.

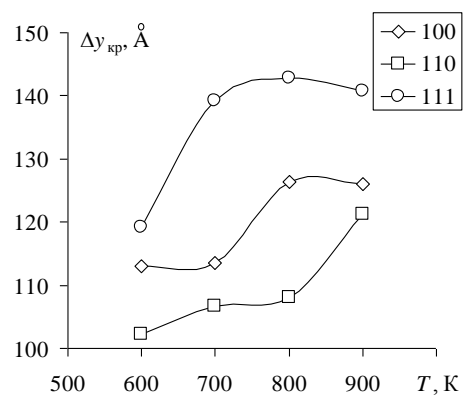

a)

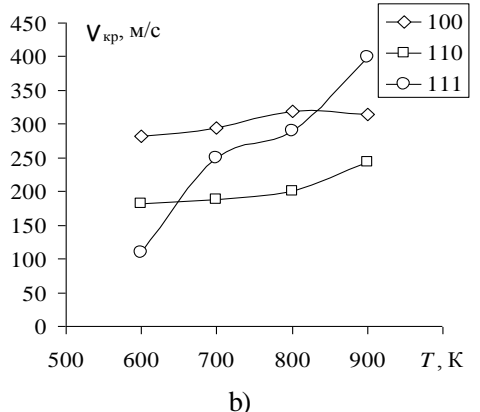

FIGURE VI. DEPENDENCE OF THE VACANCIES POSITIONS RELATIVE TO THE GB PLANE FROM TIME. 


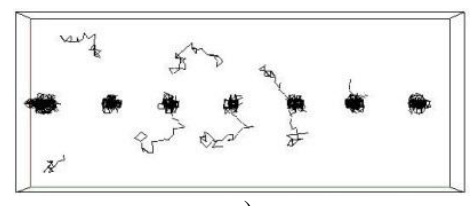

a)

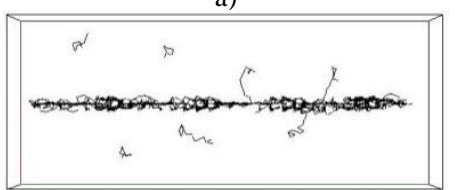

b)

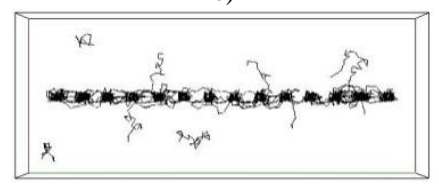

c)

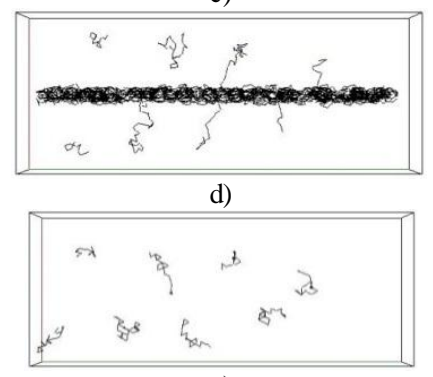

e)

FIGURE VII. THE POINT OF ENT RY OF VACANCIES IN THE GRAIN BOUNDARY.

Another feature of the vacancies interaction with GB is in what area of the border they come (Fig. 5).This is evidenced, for example, the fact that vacancies under the numbers " 3 " and "7", at first came closer to border at a distance less than the radius of capture, then again moving away from it, and then, again, came into the GB's area. It is obvious that this is due to the complex structure of boundaries. We found a few different options of entrance of vacancies in to GB's region (Fig. 7)

Fig. 7a shows low-angle boundary. As can be seen from the figure diffusion of atoms in the boundary region is concentrated in the dislocation cores. These areas are the sinks of lattice vacancies. This picture explains why some vacancies, drawing close to the border, not at once and are not necessarily captured by it, if the vacancy closer to the plane of GB at a distance less than the radius of capture, but it is far from the dislocation core, as are sult of the rmalmotion it can be moved out from the border. In this case, the edge of the capture zone has a wavy look and follows the contours of regions of compression and extension [11-12].

Fig. 7b shows the tracks of large-angle GB of general GB at small temperatures. Movement along the border is inhomogeneous. Diffusion layer thickness varies along the GB. Lattice vacancies can come in any area of such boundaries. For example, the vacancies " 1 " and "2" come to an area with a wide diffusion layer, and the vacancy " 3 " to the region, which diffusion layer is comparable to a monato mic layer.

Tracks shown in Fig. 7c and $7 d$ are typical for GB of general type with misorientation angles $30^{\circ}$ and boundaries of a special type. Rapprochement of dislocation cores such boundaries leads to the formation of a continuous diffusion layer (Fig. 7d), or nearly continuous layer (Fig. 7c). As can be seen from these figures vacancies are coming in the plane of such boundaries almost anywhere.

Finally, some boundaries are characterized by low diffusion mobility along the plane of GB (Fig. 7e). In this case, the nature of migration of lattice vacancies is not connected with the presence of GB, i.e., vacancies accidentally fall into the border.

\section{CONCLUSIONS}

The interaction of lattice vacancies with GB is generally statistical in nature. The probability of capture vacancies by boundary linearly, and the average rate of mig ration captured vacancies decreases exponentially with increasing distance.

Capture radius GB increases with increasing temperature. Exterior view of capture area depends on the type of borders and is consistent with the views of tensile of tensioncompression GBs.

Found four types of boundaries in different ways of interacting with lattice vacancies.

\section{REFERENCES}

[1] Siegel R.W., Chang S.M., Balluffi R.W. Vacancy loss at grain boundaries in quenched polycrystal-line gold // Acta Met. 1980. V.28. №3. P.249-257.

[2] Покропивный В.В., Ягодкин В.В. Моделирование взаимодействия вакансий со специальными границами наклона в объемноцентрированной кубической решетке // ФММ. 1983. Т.56. №2. С.392-396.

[3] Горбунов В.В., Даринский Б.М. Испускание вакансий межкристаллитной гранищей // ФТТ. 1992. Т.34. Вып.4. С.1059-1063.

[4] Gleiter H. Grain boundaries as point defect sources or sinks diffusional creep // Acta Met. 1979. V.27. №2. P.187-192.

[5] Демьянов Б.Ф., Грахов Е.Л., Старостенков М.Д. Взаимодействие вакансий со специальными границами зерен в алюминии // ФММ. 1999. T.88. №3. C.37-42.

[6] Suzuki A., Mishin Y. Atomistic Modeling of Point Defects and Diffusion in Copper Grain Boundaries // Interface Science. 2003. V.11. P.131-148.

[7] Мурзаев Р.Т., Назаров А.А. Энергия образования вакансий в границах наклона [001] в никеле: компьютерное моделирование // ФММ. 2005. T.100. №3. С.32-38.

[8] Мурзаев Р.Т., Назаров А.А. Энергия активации миграции вакансии в границах наклона [001] в нике-ле // ФММ. 2006. Т .101. №1 . С.96102 .

[9] Векман А.В., Драгунов А.С., Демьянов Б.Ф., Адарич Н.В. Энергетический спектр границ зерен наклона в меди // Известия вузов. Физика. 2012. Т.55. №7. С.65-71.

[10] Демьянов Б.Ф., Драгунов А.С., Векман А.В. Механизмы самодиффузии по границам зерен в алюминии // Известия Алтайского государственного университета. 2010. №1/2(65). С.158 161

[11] Орлов А.Н., Перевезенцев В.Н., Рьбин В.В. Границы зерен в металлах. М.: Металлургия, 1980. 156 с.

[12] Драгунов А.С., Демьянов Б.Ф., Векман А.В. Компьютерное моделирование внутренних поверхностей раздела в металлах и сплавах // Известия вузов. Физика. 2010. Т.53 . №3/2. С.82-87. 